\title{
PREDICTIVE ANALYSIS OF SUPERMARKET SALES
}

\author{
Sunil Bhutada, B. Samitha, Alekhya.C, Manchala meherish \\ Department of Information Technology, Sreenidhi Institute of Science \\ Technology, Ghatkesar, Hyderabad \\ sunilb@,sreenidhi.edu.in, samhitha.kasyap@gmail.com
}

Communicated: 15.03 .21

Revision : 21.04.2021

Accepted: 11.05 .2021

Published: 30.05 .2021

\begin{abstract}
:
In India and most of the Developing Countries, buying and selling of products is done in a market. This situation has many problems. These problems include the customer ending up over spending money. In order to overcome these problems, an effective Shopping Mart system is developed. This project deals with the planning, analysis and designing the way shopping in a supermarket. This is done by developing an information system database that stores and processes information about buyer's orders, sellers and products. The proposed system can be used for shopping activities by developing countries. It is an easyto-use information system that will assist buyers effectively.
\end{abstract}

Keywords: shopping, Information system, Database, Buyers, Sellers.

\section{INTRODUCTION:}

In India and most developing countries, buying and selling of goods are done in a market. The concept of exchange leads to the concept of a market. Traditionally, a market is the place where buyers and sellers gathered to exchange their goods, such as a village square.

A market consists of all the potential customers sharing a particular need or want who might be willing and able to engage in exchange to satisfy that need or want. (Kotler, 1997).

This traditional concept of a market is faced with diverse problems. These problems include:

- The customer/buyer exceeding his budget by purchasing unnecessary products.

- The necessary need for potential buyers to visit the shop which may take a lot of time, to search of a particular product in the whole market.

In order to overcome these issues we came up with this system.
The main purpose of this paper is to provide a method to reduce the time, cost and letting the customers buy what they want avoiding overspending by providing the location of any product.

PROPOSED MODEL:

Generally when a customer goes to a shopping market he tends to overspend. While in the market the customer ends up buying many items that he originally had not thought of.For instance if we go to a supermarket to buy milk, we also buy bread which is placed right next to the milk counter.this results in over spending and unwanted buying.

We proposed a website that would help us track our budget and get notified on exceeding the budget limit.

Another concern is to find the desired item it that huge supermarket. Our system also offers a solution to this problem. This website located the 
item and notifies the customer about the rack and floor details, so that it becomes easier for the customer to pick up the item without wasting time searching for it.

The currently existing systems, especially in India do not have this provision of locating the items. The already present systems only concentrate on the cost friendly shopping idea.

Our idea focuses both on cost and time saving shopping techniques.

Another major idea behind developing this website is to be beneficial to the customers .It provides many services such as displaying the available discounts notifying on crossing the budget limit mentioned earlier by the customer and also provides the exact location of the product selected by the customers avoiding searching. While the customer searches for his desired item he tends to pick up two other items that he had no plan to buy, thereby spending more money. Situations like this can be avoided by using our dashboard/website.

\section{SYSTEM AND ARCHITECTURE: SYSTEM:}

This website is built using

- python and flask to develop the back end

- HTML, CSS, PHP, JS to create front end

- MySQL, SQLite3 to maintain the database.

This has many features such as: Login page, Dashboard Checklist, Cost calculation and Location tracker.

When the customer enters the website, he sees the login page wherein he gets an option whether to login or to register. Once that step is completed the person must enter the approximate budget for that session of shopping. Now a screen appears which consists of the list of items in the supermarket which is retrieved from the database of the website. The customer can add the items into the cart that he wishes to buy. There is an option to even remove the items which he no longer wants to shop. A notification pops up if the customer exceeds the already mentioned budget. In this case a brief analysis of the budget is given to the customer, through which he can alter his shopping list. Upon confirmation from the customer the rack numbers for every item is displayed, which helps the customer in easily locating the item hence saving time. Once the shopping is done the customer can checkout.

\section{ARCHITECTURE:}

The website comprises of various modules such as

a) User Login/Registration:

Here the customer logins in if in case he already has an existing account or else he can register in case if he is a new user.

b) Dashboard:

This is the main page of the website. The user can navigate to other modules from here.

c) Budget:

This is the module which calculates the budget. Depending upon the total number of items in the cart the cost varies. The customer must enter his budget during the start of the shopping process.

d) Cart:

Customer ads all the items that he would like to purchase into the cart. All these items are managed by this module.

e) Cost Analysis:

The cost of the items in the cart is analyzed depending upon the budget of the customer. It determines if the cost exceeds the budget or not.

f) Notification:

If in case the cost exceeds the mentioned budget there is a notification which appears cautioning the customer about the

Overspending of money. All this is managed by this module.

g) Pointing out the rack number of the item: 
I J R B A T, Issue (IX), Vol. II, May 2021: 74-

A Double-Blind Peer Reviewed \& Refereed Journal

For easy locating of the items by the customer, the rack number of the items are retrieved from the database and are displayed on the screen. This saves a lot of customer's time.

The figure shows the architectural diagram of the system.

Once the customer pickups all the items he can then checkout from the website and pay at the bill counter.

\section{RESULTS:}

The customer when enters the website can see a dashboard from where he can navigate throughout the website.

This page also displays any available discounts.

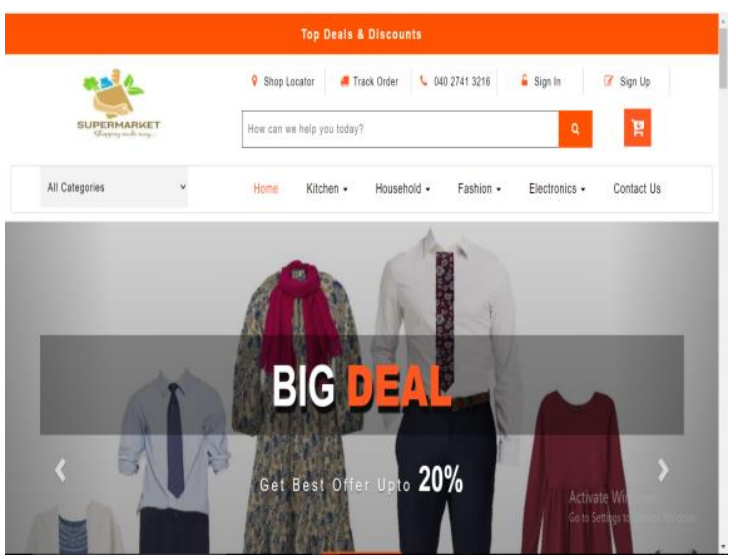

Fig 2: Dashboard

After entering the budget the customer now can select items from the available list of item and add them to the cart.

\section{Our Top Products}

$\rightarrow 4$.
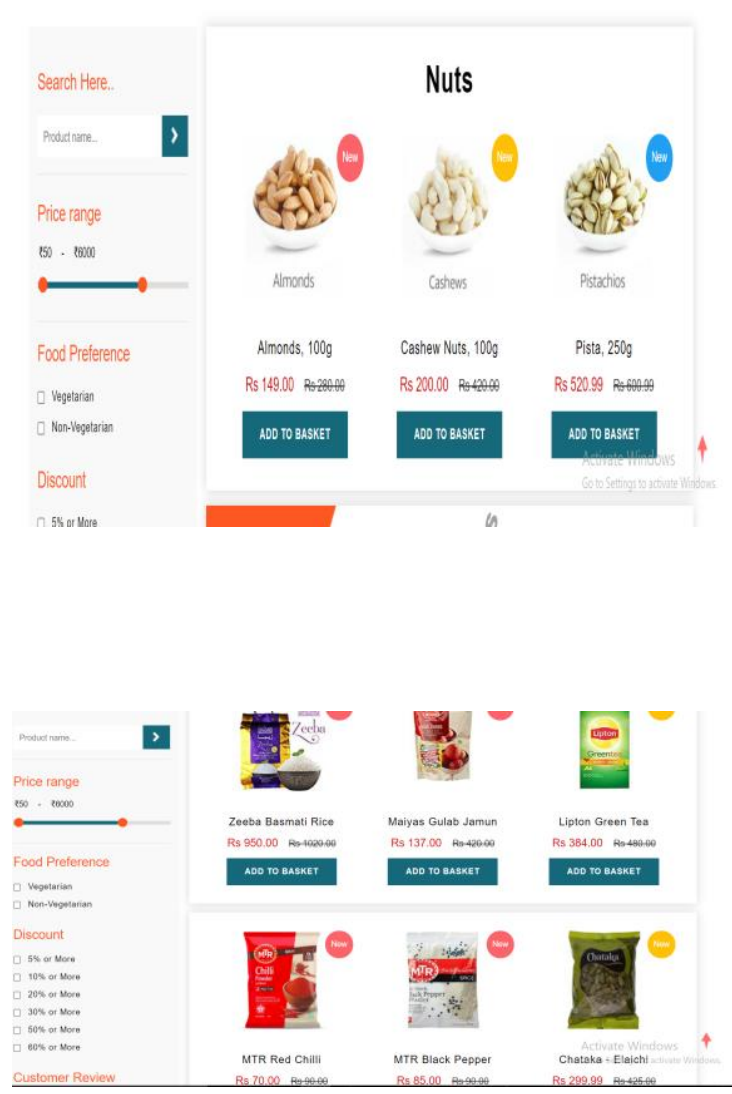

Fig 3: List of Items Available

Now the items can be added to the cart, which can be purchased later.

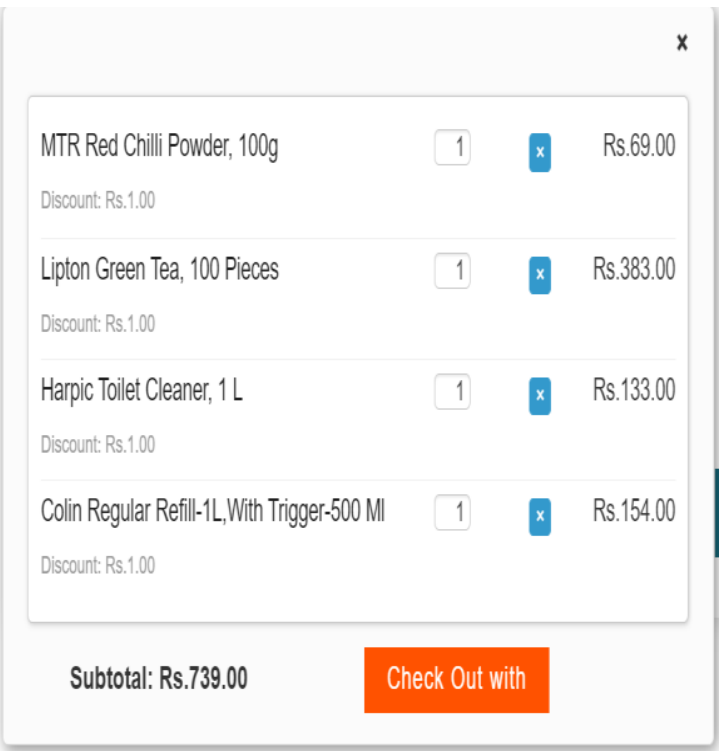


I J R B A T, Issue (IX), Vol. II, May 2021: 74-

A Double-Blind Peer Reviewed \& Refereed Journal
OPEN $\bigcirc$ ACCES

e-ISSN $2347-517 X$

Original Article
Fig 4: List of Items in Cart.

A detailed budget analysis is done which improves the efficiency and quality of shopping.

\section{Budget Analysis}

Your shopping cart contains: 3 Products

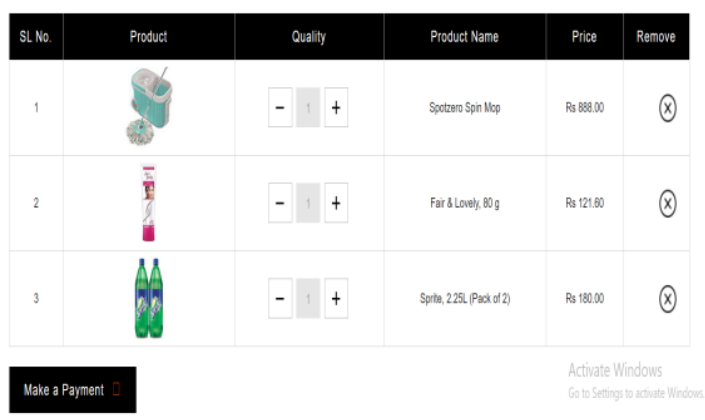

Fig 5: Budget analysis

\section{FUTURE SCOPE AND CONCLUSION:}

This website can be used to enjoy a cost and time saving shopping experience. The features in the system enables the customer to get notified on crossing the limit while spending money.

This project can be further developed in future by adding additional features such as being able to locate the item and depicting it through a graph, and also collaborating with more than one super market to compare the cost among them and suggest the best and inexpensive place for shopping.

\section{REFERENCES:}

Project: Flower Species Segmentation and Classification Viraj Mavani Viraj Mavani Ayesha Gurnani Ayesha GurnaniJhanvi Shah

Flower Recognition System Based on Image Processing Tanakorn Tiay, Pipimphorn Benyaphaichit and Panomkhawn Riyamongkol

A Technical Review on Text Recognition from Images Pratik Madhukar Manwatkar K.

R. SinghK. R. Singh

A Review Paper on Face RecognitionTechniques Vijay H Mankar Vijay H Mankar Sujata BheleSujata

R. Sharma, B. Kaushik and NGondhi, "Character Recognition using Machine learning and Deep lear. ning"

S. L. Wasankar, H. Mahajan, D. Deshmukh and Munot, "Machine learning with text recognition", 2010 IEEE International Conference on Computational Intelligence and Computing Research.

Video text recognition using feature compensation as category-dependent feature extraction M. Mori

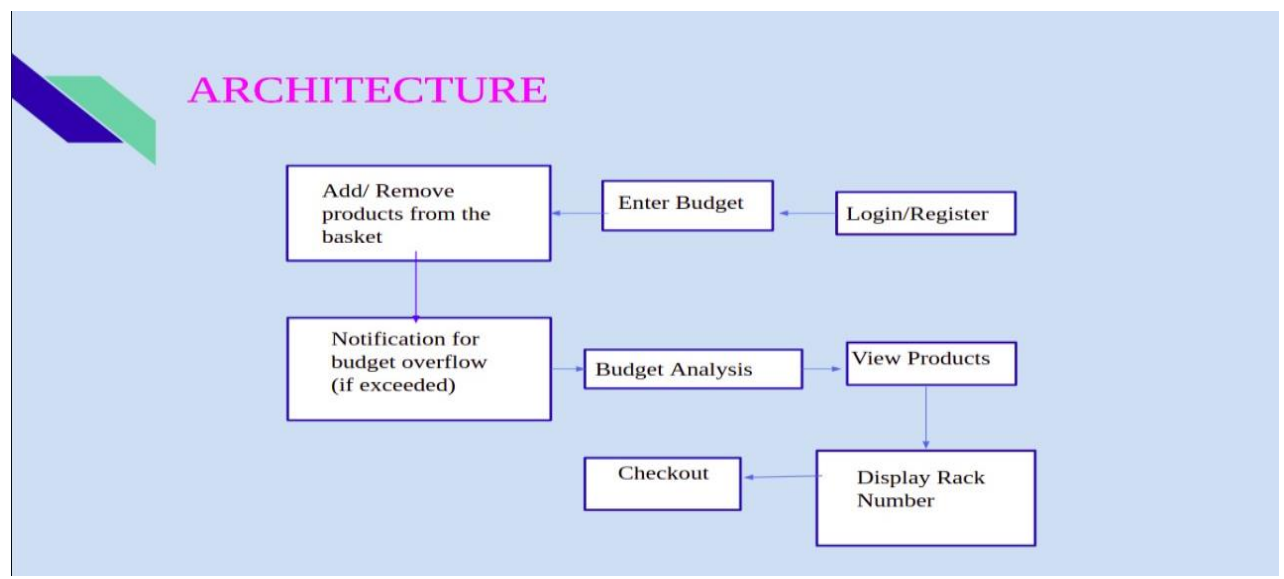

